\title{
Reply to 'Comment on: Carotid-cavernous fistula: current concepts in aetiology, investigation and management'
}

\author{
Amanda D. Henderson ${ }^{1} \cdot$ Neil R. Miller ${ }^{1}$ \\ Received: 23 April 2018 / Accepted: 23 April 2018 / Published online: 22 May 2018 \\ (c) The Royal College of Ophthalmologists 2018
}

We appreciate the comments by Gout et al. [1] We agree that some superior ophthalmic veins are extremely fragile and difficult to cannulate, even with the available microcatheters (see supplemental video). We also agree that performing a Valsalva maneuver may make it easier to insert the microcatheter into the vessel. One still must be careful not to perforate the vessel as the catheter is advanced, as catastrophic visual complications can result, as emphasized in our manuscript and in the paper by Leibovitch et al., which we (and Gout et al.) have referenced [2].

Electronic supplementary material The online version of this article (https://doi.org/10.1038/s41433-018-0113-4) contains supplementary material, which is available to authorized users.

Neil R. Miller

nrmiller@jhmi.edu

1 Division of Neuro-Ophthalmology, Wilmer Eye Institute, Johns Hopkins School of Medicine, Baltimore, MD, USA

\section{Compliance with ethical standards}

Conflict of interest The authors declare that they have no conflict of interest.

\section{References}

1. Gout T, Patankar T, El-Hindy N, Galantzis G. Carotid-cavernous fistula: current concepts in aetiology, investigation and management. Eye. 2018.

2. Leibovitch I, Modjtahedi S, Duckwiler GR, Goldberg RA. Lessons learned from difficult or unsuccessful cannulations of the superior ophthalmic vein in the treatment of cavernous sinus dural fistulas. Ophthalmology. 2006;113:1220-6.

\section{Electric cataracts: a cause of bilateral blindness in Kashmir}

\author{
Rayees Sofi ${ }^{1} \cdot$ Tariq Qureshi ${ }^{1} \cdot$ Viney Gupta $\mathbb{D}^{2}$
}

Received: 27 February 2018 / Accepted: 28 February 2018 / Published online: 23 May 2018

(c) The Royal College of Ophthalmologists 2018

\section{Viney Gupta}

gupta_v20032000@yahoo.com

1 Government Medical College Srinagar, Srinagar, Jammu and Kashmir, India

2 Dr. Rajendra Prasad Centre for Ophthalmic Sciences, All India Institute of Medical Sciences, New Delhi, India
Electrical injury is not uncommon as many people come into contact with electricity on daily basis. However only few cases of electrical cataract have been reported because very few patients survive after a high electric voltage, that is needed to induce cataract [1-3]. Most of the cases of electrical injury have no visual complaints in the early 